THE WORLD BANK ECONOMIC REVIEW, VOL. 2, NO. $1: 105-121$

JAN. 1988

\title{
External Shocks and the Demand for Adjustment Finance
}

\author{
Ricardo Martin and Marcelo Selowsky
}

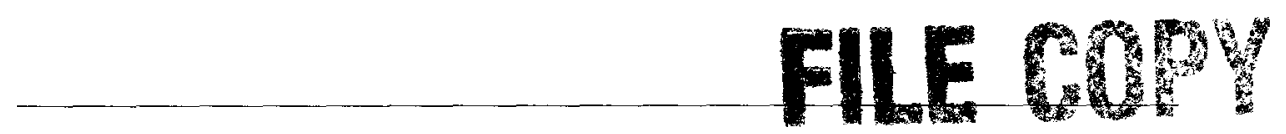

When a country experiences a long-term adverse external shock, resulting in a balance of payments deficit unsustainable in the medium term, how quickly should it adjust? Because time is required for movement of productive factors and consumption patterns, the short-term effect of the shock will be a large increase in the value of foreign exchange. It then pays to borrow abroad during the first years of the transition against those years when full resource and demand reallocations have taken place. To allow this adjustment path, the market exchange rate should follow the shadow exchange rate. This article uses a simple traded/nontraded sector model with lagged responses and optimal borrowing theory to derive a quantitative relationspip between the magnitude of the shock and the optimal amount of borrowing, the speed at which the original shortfall of foreign currency should be closed, and the required currency depreciation during the borrowing and repayment period.

The appropriate mix of instruments and the speed at which to close an unsustainable deficit in the balance of payments has recently received considerable attention. These questions become more important when that deficit results from an external shock that is expected to last for several years or even reflect a new medium-term external scenario for the country in question. The adjustment calls for a substantial medium- or long-run restructuring or reallocation of resources in the economy.

To a large extent, discussions of these issues have centered on the appropriateness of present adjustment programs, particularly those faced by developing countries as a result of a worsening external scenario during the $1980-85$ period. Balassa (1986), for example, compares the size of shocks and the way countries responded to them, and Kharas and Shishido (1985) assess alternative borrowing strategies followed by Thailand as a reaction to the external shocks of the late 1970s. Implicit in these discussions is the notion that some of these programs might have entailed an excessive welfare cost and that less costly transition paths might exist to reach a sustainable equilibrium compatible with the new medium-term external conditions.

Ricardo Martin is an economist and Marcelo Selowsky Chief Economist in the Latin American and the Caribbean Regional Office of the World Bank.

(C) 1988 The International Bank for Reconstruction and Development / THE WORLD BANK. 
A specific hypothesis is that a more gradual adjustment program to close the deficit, which relies less on strong short-term expenditure contraction and expenditure switching policies but requires extra external borrowing, might have benefits that more than compensate for the cost of this extra credit. The real issue is whether this demand for adjustment funds is high enough to be justified at a nonconcessionary cost of credit. If countries are willing to pay, let us say, 10 percent real interest to finance these programs, but because of risk perceptions they have credit constraints from commercial sources of finance, this demand for adjustment finance could be interpreted as a case for the type of new lending programs of multilateral institutions such as the Structural Adjustment Lending Program of the World Bank.

The purpose of this article is to explore such a case. We develop a simple traded/nontraded sector model with lagged elasticity response plus an application of optimal borrowing theory to derive a quantitative relationship between the magnitude of the external shock and the optimal amount of external borrowing.

When faced with a permanent external shock, a country can choose different speeds at which to close the resulting balance of payments gap. It can attempt to close it rather quickly with strong short-term contractionary and rapid exchange rate devaluation policies. If the elasticity response of the traded sector is low in the short run, most of the adjustment will have to come from contractionary policies that lower the consumption of exportables and importables. If these policies call for a decline in the nominal prices of nontraded goods and these prices are inflexible, and it takes time for resources in these sectors to move toward the traded sectors, some unemployment of resources will occur in the nontraded sector. Alternately, the possibilities of achieving strong real devaluations in the short run might be limited by the behavior of nominal wages. Increases in nominal wages must be kept below increases in the nominal exchange rate if a real devaluation is the goal. If workers' consumption basket consists largely of traded goods, nominal wages will tend to follow the nominal exchange rate. Downward pressures on the nominal wage will emerge only when the labor market begins to adjust in the face of unemployment, and this might also take time.

The model to be developed here will only capture part of the forces described earlier that may call for a slower adjustment path. The analysis focuses on the effect of the time it takes for resources to move from the nontraded to the traded sector; the long-run elasticity response of the traded sector might be substantially larger than the sector's short-term response. In the first years after the shock the scarcity (shadow) price of foreign exchange might be substantially higher than in the medium and long terms, as resources begin to move from the traded to the nontraded sector. It then pays for the country to borrow during these first years, when foreign exchange is scarce, against the medium term when the adjustment to the new external situation has taken place. It is this differential 
scarcity of foreign exchange that determines the rationale for borrowing; adding the cost of the short-term unemployment described earlier might be an added argument for borrowing, not being considered here.

With or without borrowing, the new shadow or scarcity price of foreign exchange will be higher in the long run than the pre-shock equilibrium level. What is important for this exercise is that the market exchange rate is allowed to move: no additional tariffs or import restrictions are used in lieu of the market exchange rate in order to close the balance of payments. Only in this way will resources be pulled into the traded sectors.

The article is organized as follows. Section I defines the features of the economy in question; section II discusses the determinants of optimal external borrowing; section III analyzes the effect of the external shock on borrowing; section IV presents empirical results and a sensitivity analysis; and section V summarizes the main conclusions. The appendix presents the formal model used to derive the quantitative results.

\section{The General Framework}

The economy is small in relation to international markets, and has two types of traded goods, "importables" and "exportables," and one nontraded sector. The only distortion in the economy is a tariff on imports. Consequently, that tariff generates a wedge between the market exchange rate and the shadow exchange rate. These tariffs are kept constant throughout the analysis.

By selecting units so that the international prices of exportables and importables are equal to one, we define three domestic relative prices, of which only one is endogenous (in these definitions the subindexes $N, X$, and $I$ are used to denote goods as nontraded, exportables, and importables, respectively):

$$
\frac{P_{X}}{P_{N}}=P,
$$

which is endogenous and equal to the real market exchange rate.

$$
\frac{P_{I}}{P_{X}}=(1+T)
$$

where $T$ is the import tariff. On the basis of equations 1 and 2, we obtain:

$$
\frac{P_{I}}{P_{N}}=P(1+T)
$$

Thus having determined $P$, the other relative prices are automatically determined.

Market equilibrium in the nontraded market is defined as:

$$
E_{N}(P, y)=0
$$


where $E_{N}$ is the excess demand for nontraded goods and $y$ is real income. Balance of payments equilibrium is written as:

$$
E_{I}(P, y)+E_{X}(P, y)=F-Z
$$

where $E_{I}$ and $E_{X}$ are the excess demand functions of importables and exportables, $F$ is the planned borrowing under the pre-shock situation, and $Z$ is the unpredicted gap (shock) in the balance of payments.

The effect of the shock can be obtained by differentiation of equations 4 and 5 . The endogenous variables are $P$, the exchange rate, and $y$, real income. The policy variable is $F$, which will be revised as a result of the shock.

\section{Optimal External Borrowing}

It is assumed that the economy was on an optimal borrowing path prior to the reform. We can evaluate the effect of the external shock on that path.

On an optimal borrowing path, there cannot be any unexploited opportunity for intertemporal arbitrage in terms of traded goods. Borrowing will take place up to the point at which the marginal utility of a unit of foreign exchange borrowed today is equal to the discounted value of the utility forgone when that unit is repaid in any future period $t$. Thus we must have:

$$
\lambda_{o} P_{o}^{*}=\lambda_{t} P_{t}^{*}\left(\frac{\rho}{\delta}\right)^{t} \text { for all } t,
$$

where $\lambda$ is the marginal utility of income, $P^{*}$ is the scarcity (shadow) relative price of traded goods, $\rho$ is equal to one plus the cost of borrowing, and $\delta$ is one plus the pure rate of time preference. This equality depends on the assumption that $\rho$ is exogenous, that is, that the country does not face a quantitative ceiling on its external borrowing, at least in the relevant range.

Note that because of the tariff, $T$, the market real exchange rate, $P$, entering equations 4 and 5 is different from the shadow exchange rate, $P^{*}$, which is the relevant price entering equation 6 and thus determining the optimal borrowing plan. The relation between the two rates is described in the appendix and can be written as:

$$
P_{t}^{*}=\frac{e_{X X}}{e_{X X}+e_{I I}} P_{t}+\frac{e_{I I}}{e_{X X}+e_{I I}} P_{t}\left(1+T_{t}\right)
$$

where $e_{I I}$ is the own-price elasticity of the excess demand for importables (the demand for imports) and $e_{X X}$ the own-price elasticity of the supply of exports (the excess demand for exportables). This expression assumes that the crossprice elasticity of the excess demand of exportables with respect to importables is zero. Where tariffs are always fully rebated to consumers, as in our model, the real income of the private sector remains constant. Consequently these elasticities refer to compensated demands. For mathematical purposes, both elasticities 
are defined positive (see Dornbusch 1974 and van Wijnbergen 1984 for a discussion of the shadow exchange rate in this type of model).

Equation 7 shows that the shadow exchange rate is equal to a weighted average of the relative prices of exportables, $P$, and importables, $P(1+T)$, where the weights are proportional to $e_{X X}$ and $e_{I I}$. This can be more intuitively discussed with the help of figure 1.

Figure 1 illustrates the effect of the import tariff on the supply of and demand for foreign exchange, the relation between the shadow market and real market exchange rates, and the impact of foreign borrowing. The domestic demand for imports is represented by the curve $D$. The curve $\hat{D}$ shows, for any level of import demand, the price that is actually paid to the foreign exporter-that is, the vertical difference between the two curves is the amount of import tariff. In the absence of any capital flows, equilibrium occurs at the intersection of the $S$ curve, which shows the supply of foreign exchange, and the $\hat{D}$ curve, for here the demand for and supply of foreign currency are equal. (Recall the assumption that units of imports and exports are defined so that their prices in foreign exchange are unity.) At this equilibrium, $P_{0}$ is the price of exports and the real market exchange rate and $P_{0}(1+T)$ the internal price of imports and hence the marginal valuation of importables.

When an amount, $\Delta$, of additional foreign exchange becomes available through borrowing, the supply of foreign currency curve moves to $S+\Delta$ with a new equilibrium price of $P_{1}$. Demand for imports increases by $b$, whereas the supply of imports falls by $a$. The shaded area is the valuation of the additional

Figure 1. Foreign Exchange Markets, Borrowing, and the Shadow Exchange Rate

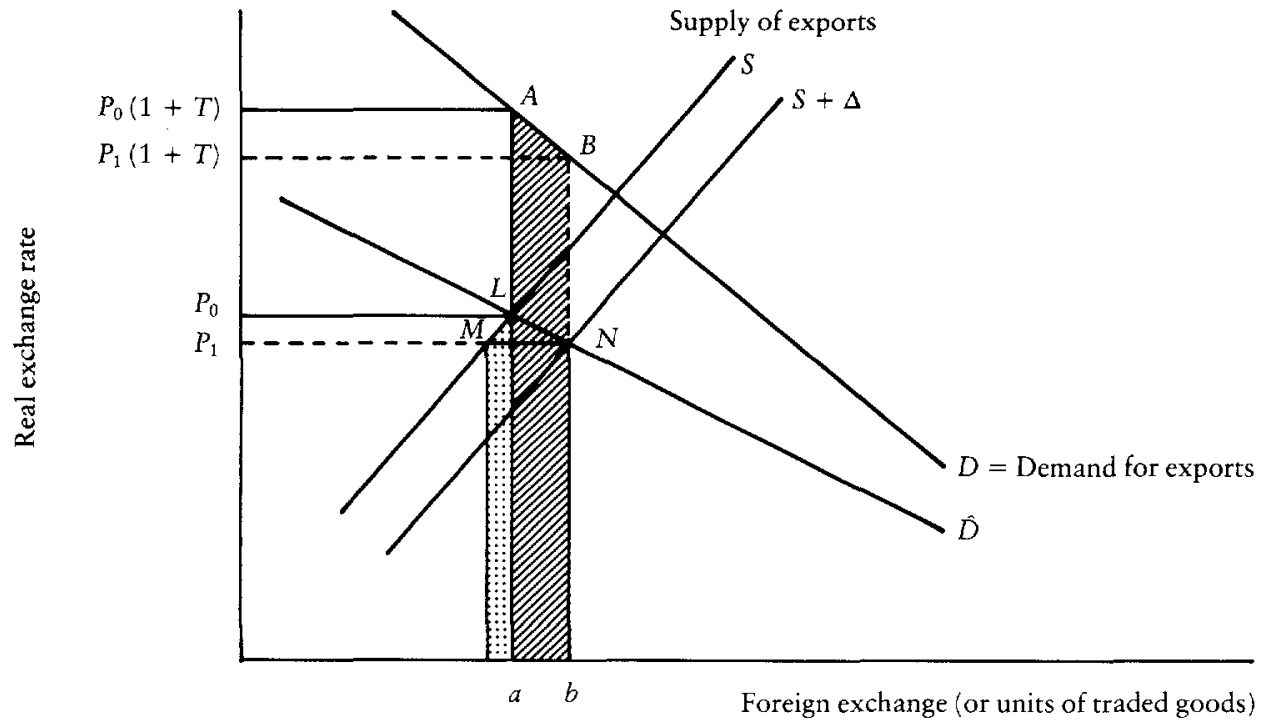


imports; the dotted area is the value of resources released from exports that are now available for domestic demand. The total benefit of the additional foreign exchange is the sum of the two areas: when divided by $\Delta$, the amount of the increase, this yields the additional benefit of a unit, that is, the shadow price of foreign exchange. When $\Delta$ is small, this is a weighted average of $P_{0}$ and $P_{1}(1+T)$, where the weights are functions of the relative elasticities of demand for and supply of foreign exchange (or the elasticities of excess supply of importables and demand for importables).

\section{The Effect of the External Shock}

We assume the country was originally on an optimal borrowing path prior to the shock. The issue is to what extent the shock calls for a reformulation of that plan, or whether the new time path of the shadow exchange rate might call for extra borrowing. As we illustrate below, that time path will crucially depend on the speed at which the economy's resources move as a result of changes in the new level of the real market exchange rate.

Figure 2 shows again the market for foreign exchange. $P_{0}$ is the market equilibrium exchange rate, given the structure of tariffs, that would have prevailed without the shock $Z$. That equilibrium incorporated positive borrowing out of the original optimal borrowing plan. $P_{0}^{*}$ is the optimal shadow exchange rate associated with $P_{0}$ and the structure of tariffs.

Figure 2. Behavior of the Exchange Rate under the External Shock and Before Extra Borrowing

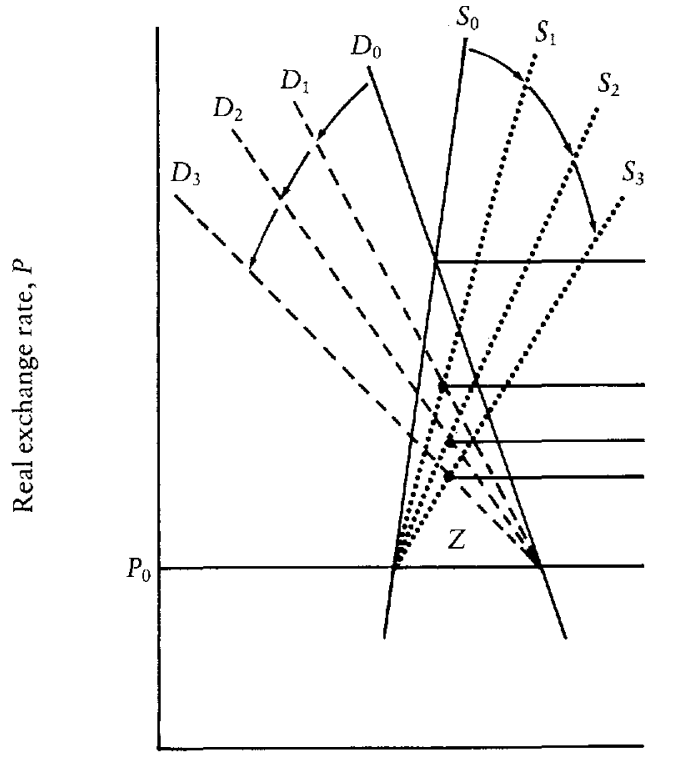

Quantity of foreign exchange

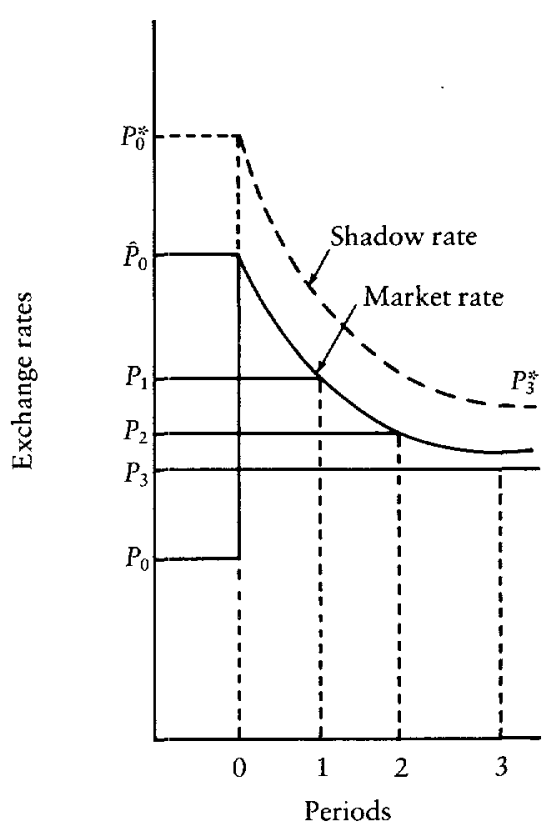


$S_{0}$ and $D_{0}$ reflect the short-run supply and demand for foreign exchange immediately after the shock. If the excess demand for foreign exchange, $Z$, were to be immediately closed, the new market exchange rate would be $\hat{P}_{0}$. As resources begin to move toward the traded sector in response to the new (higher) real market exchange rate, both supply and demand increase their elasticity response; that is, they gradually rotate around the original level of the market exchange rate. Thus in period 1 the required real market exchange rate becomes $P_{1}$; as time passes and further resources move, the new required level becomes $P_{2}$. If it takes three periods to complete the adjustment, and $S_{3}$ and $D_{3}$ would represent the long-run supply and demand schedules, and the new real market rate for the economy which will result is $P_{3}$. The shadow rate follows the same behavior as the market rate given that the structure of tariffs remains invariant. ${ }^{1}$

If the economy were instantaneously to adjust to the new equilibrium values $P_{3}$ and $P_{3}^{*}$, no justification for extra borrowing would exist. An immediate new and constant scarcity price of foreign exchange does not disturb the optimal borrowing condition 7 and thus does not call for extra borrowing. However, if it takes time for the market and shadow rates to converge to their new values, equation 7 will indeed be disturbed; it will then pay to borrow during the first years after the shock, against the period when the scarcity price of foreign exchange is lower. The rationale for borrowing is not the shock per se, but the fact that it takes time for the economy to adjust to the new external conditions.

A key assumption in this analysis is that changes in the elasticities of the exportable and importable sectors are exogenous and only a function of time. In other words, the short-term schedules converge toward the long-run ones only over time, independently of other variables in the economy. For example, when the extra borrowing evens out the path of the market real exchange rate, we assume this "smoothing" does not affect the speed at which the short-run values converge to the long-run ones; that is, the increase in elasticity response is independent of the path of prices or incentives. What matters is for the market real exchange rate in any single year after the shock to be higher than the preshock equilibrium level.

\section{Simulation Results}

\section{Parameter Values and Assumptions: Base Case}

Table 1 shows the parameter values used in the base case in order to obtain estimates of the extra optimal borrowing induced by the external shock. It is assumed that both the excess demands for both importables and exportables have short-run elasticities of 0.2 and long-run elasticities of 0.6 . The speed of adjustment coefficient of 0.4 means that, in each period, the short-term elastici-

1. The proportionality between the shadow and market exchange rates, $P_{t}^{*}$ and $P_{t}$, will only change because of changes in the differential elasticity response between imports and exports as time passes. In this case the weights attached to $P_{t}$ in equation 7 will change. 
Table 1. Parameter Values: Base Case

\begin{tabular}{lc}
\multicolumn{1}{c}{ Parameter } & Value \\
\hline Elasticity of excess demand importables & \\
$\quad$ Short-run & 0.2 \\
$\quad$ Long-run & 0.6 \\
Elasticity of excess demand exportables & 0.2 \\
$\quad$ Short-run & 0.6 \\
Long-run & 0 \\
Cross-elasticity between exportables and importables & 0.4 \\
Speed of adjustment & -1.0 \\
Elasticity of the marginal utility of income & 1.0 \\
Income elasticity of nontraded goods & 1.0 \\
Income elasticity of importables & 0.1 \\
Interest rate on borrowing & 0.2 \\
Import tariff & 0.5 \\
Production & 0.4 \\
Share of nontraded in GNP & 0.1 \\
Share of exportables in GNP & \\
Share of importables in GNP & 0.4 \\
Expenditure & 0.3 \\
$\quad$ Expenditure share on importables &
\end{tabular}

ties increase by a fraction 0.4 of the difference between the long-run and present value, that is, approach asymptotically their long-run values. Two values for the elasticity of the marginal utility of income are used, 0 and -1 ; the latter is used for the base case. ${ }^{2}$

The base case assumes a zero cross-price elasticity between exportables and importables; this implies that both commodities are independent in consumption (a change in the price of one commodity does not affect the demand for the other commodity) and that both sectors do not compete for the same primary inputs. This case represents best an economy where tariffs are concentrated on manu-

2. Positive present savings can be expected if the discounted utility of one dollar saved is larger than the utility of consuming it today. Denoting $r$ the rate of return and $d$ the pure rate of time preference, this will be true of:

$$
\left(\frac{1+r}{1+d}\right) \lambda_{1}>\lambda_{0} \quad \text { or } \quad\left(\frac{1+r}{1+d}\right) \frac{\lambda_{1}}{\lambda_{o}}>1
$$

where $\lambda_{t}$ is the marginal utility of consumption in period $t$. Denoting $\phi$ as the elasticity of the marginal utility of income (consumption) and $g$ as the annual growth rate of consumption, then $\left(1^{\prime}\right)$ can be rewritten as:

$$
\begin{gathered}
\left(\frac{1+r}{1+d}\right)(1-\phi g)>1 \\
r>(d+\phi g),
\end{gathered}
$$

where $(d+\phi g)$ can be called the consumption discount rate. If $\phi=0$, savings behavior will be independent of the expected growth of consumption. Some large values of $d$ can also be ruled out. If $\phi>2, g=0.03$, and $r=0.10$, no savings are expected unless the rate of time preference is below 0.04 . 
factures and where exports are agricultural goods. Cross-price elasticities of zero will always hold if the country does not consume the exportable good and does not produce the importable good. However, the results did not appear to be particularly sensitive to this assumption of zero cross-elasticities.

The production and expenditure values used in the base case characterize a rather small, open type of economy that is sensitive to external factors. Traded goods are a high proportion of total output and exports and imports represent a high fraction of gross national product (GNP). Movements in terms of trade are translated into large shocks as a fraction of GNP.

The borrowing to be derived from the optimal rule 6 must obey a budget constraint relating future repayment flows to the amount borrowed and the interest rate (equation A-11 in appendix). This requires specifying a horizon or repayment period over which this constraint holds-the period over which the present discounted value of the extra borrowing and its repayment becomes zero.

\section{Results}

Table 2 shows values for optimal yearly borrowing as a percentage of the extra gap in the balance of payments due to the external shock. The positive figures indicate borrowing, the negative ones indicate the resulting repayment flows.

The effect of alternative assumptions regarding the difference between short-

Table 2. Optimal Annual Borrowing as a Percentage of the External Shock

\begin{tabular}{|c|c|c|c|c|c|c|c|c|c|c|}
\hline \multirow[b]{2}{*}{ Parameters varied } & \multicolumn{10}{|c|}{ Borrowing and repayment periods (years) } \\
\hline & 1 & 2 & 3 & 4 & 5 & 6 & 7 & 8 & 9 & 10 \\
\hline \multicolumn{11}{|l|}{$\begin{array}{c}\text { Difference in short-run and } \\
\text { long-run supply and } \\
\text { demand elasticities }^{\mathrm{a}}\end{array}$} \\
\hline Base case: $0.2,0.6$ & 32 & 2 & -10 & -16 & -20 & & & & & \\
\hline Small difference: $0.5,1.0$ & 14 & 1 & -4 & -7 & -9 & & & & & \\
\hline Large difference: $0.2,1.0$ & 42 & 0 & -14 & 20 & -23 & & & & & \\
\hline $\begin{array}{l}\text { Inelastic marginal utility of } \\
\text { income }(=0)^{\mathrm{b}}\end{array}$ & 50 & 10 & -14 & -29 & -37 & & & & & \\
\hline $\begin{array}{l}\text { Speed of convergence from } \\
\text { short- to long-run } \\
\text { elasticities }\end{array}$ & & & & & & & & & & \\
\hline \multicolumn{11}{|l|}{ Moderate $(=0.4$ a year $)$} \\
\hline 3-year repayment & 25 & -8 & -21 & & & & & & & \\
\hline 5-year repayment & 32 & 2 & -10 & -16 & -20 & & & & & \\
\hline 10-year repayment & 37 & 10 & 1 & -7 & -10 & -12 & -13 & -13 & -14 & -14 \\
\hline \multicolumn{11}{|l|}{ Low $(=0.2$ a year $)$} \\
\hline 3-year repayment & 17 & -3 & -16 & & & & & & & \\
\hline 5 -year repayment & 24 & 6 & -6 & -14 & -20 & & & & & \\
\hline 10 -year repayment & 31 & 15 & 4 & -3 & -8 & -12 & -15 & -17 & -19 & -20 \\
\hline
\end{tabular}

Note: positive values indicate borrowing; negative values indicate repayment.

a. Supply and demand elasticities are assumed to be the same; we allow the short and long run to vary.

b. Assumed to be equal to -1.0 in the base and other cases. 
and long-run elasticities are first explored. For the base case, the optimal borrowing during the first year is 32 percent of the balance of payment gap, that is, 68 percent of the gap must be closed during the first year through a real devaluation. If the permanent gap were equal to $\$ 300$ million, the optimal strategy would be for the country to borrow $\$ 96$ million during the first year, $\$ 6$ million during the second year, and start repaying it by the third year. As shown, the results are quite sensitive to the differences between the short- and long-run elasticities. When the long-run elasticity is 1.0 instead of 0.6 , the optimal borrowing during the first year increases from 32 to 42 percent of the shock.

Table 2 also indicates the effect of changing the value of elasticity of the marginal utility of income from 1.0 to 0 . When this value is zero, there is no benefit to be obtained by equalizing incomes over time, and no penalties associated with an increase in intertemporal income inequality. In this case, borrowing only responds to intertemporal differences in the scarcity price of foreign exchange; no penalty is attached to the fact that borrowing transfers income from the future to the present, thus creating an intertemporal inequality in income. The effect of this condition is a large level of borrowing. In this case, the increase in borrowing is substantial, equal to 50 percent of the shock during the first year.

Different speeds of convergence of the short-run to the long-run elasticity will also affect optimal borrowing strategies. A slower coefficient of convergence (equal to 0.2) makes the level of borrowing quite sensitive to the limit of the period of repayment. Although the long-run elasticity of supply and demand is still the same, it takes longer to achieve that long-run level, and the effective response to the foreign exchange gap during the borrowing-repayment period is much smaller. Given the low convergence rate, as the repayment period increases from 3 to 10 years, the borrowing during the first year increases from 17 to 31 percent of the shock.

\section{Behavior of the exchange rate}

Table 3 and figure 3 show the behavior of the market and shadow real exchange rate with and without the additional external borrowing. We assume

Table 3. Response of the Market and Shadow Exchange Rates to an External Shock (market rate in the base period $=100)$

\begin{tabular}{|c|c|c|c|c|c|}
\hline \multirow[b]{2}{*}{ Period } & \multicolumn{2}{|c|}{$\begin{array}{c}\text { Without } \\
\text { borrowing }\end{array}$} & \multicolumn{2}{|c|}{$\begin{array}{c}\text { With } \\
\text { borrowing }\end{array}$} & \multirow{2}{*}{$\begin{array}{c}\text { Borrowing as a } \\
\text { percentage of GNP }\end{array}$} \\
\hline & Market & Shadow & Market & Shadow & \\
\hline $\begin{array}{c}0 \\
\text { (pre-shock) }\end{array}$ & 100 & 109 & 100 & 109 & \\
\hline 1 & 130 & 142 & 119 & 129 & 1.6 \\
\hline 2 & 115 & 125 & 114 & 125 & 0.1 \\
\hline 3 & 111 & 121 & 112 & 123 & -0.5 \\
\hline 4 & 110 & 120 & 111 & 122 & -0.8 \\
\hline 5 & 109 & 119 & 111 & 121 & -1.0 \\
\hline
\end{tabular}

Note: Parameter values are as in the base case (see table 1). The shock creates a gap or shortage of foreign exchange at current exchange rates equal to 5 percent of GNP. 
Figure 3. Response of the Market and Shadow Exchange Rates to an External Shock

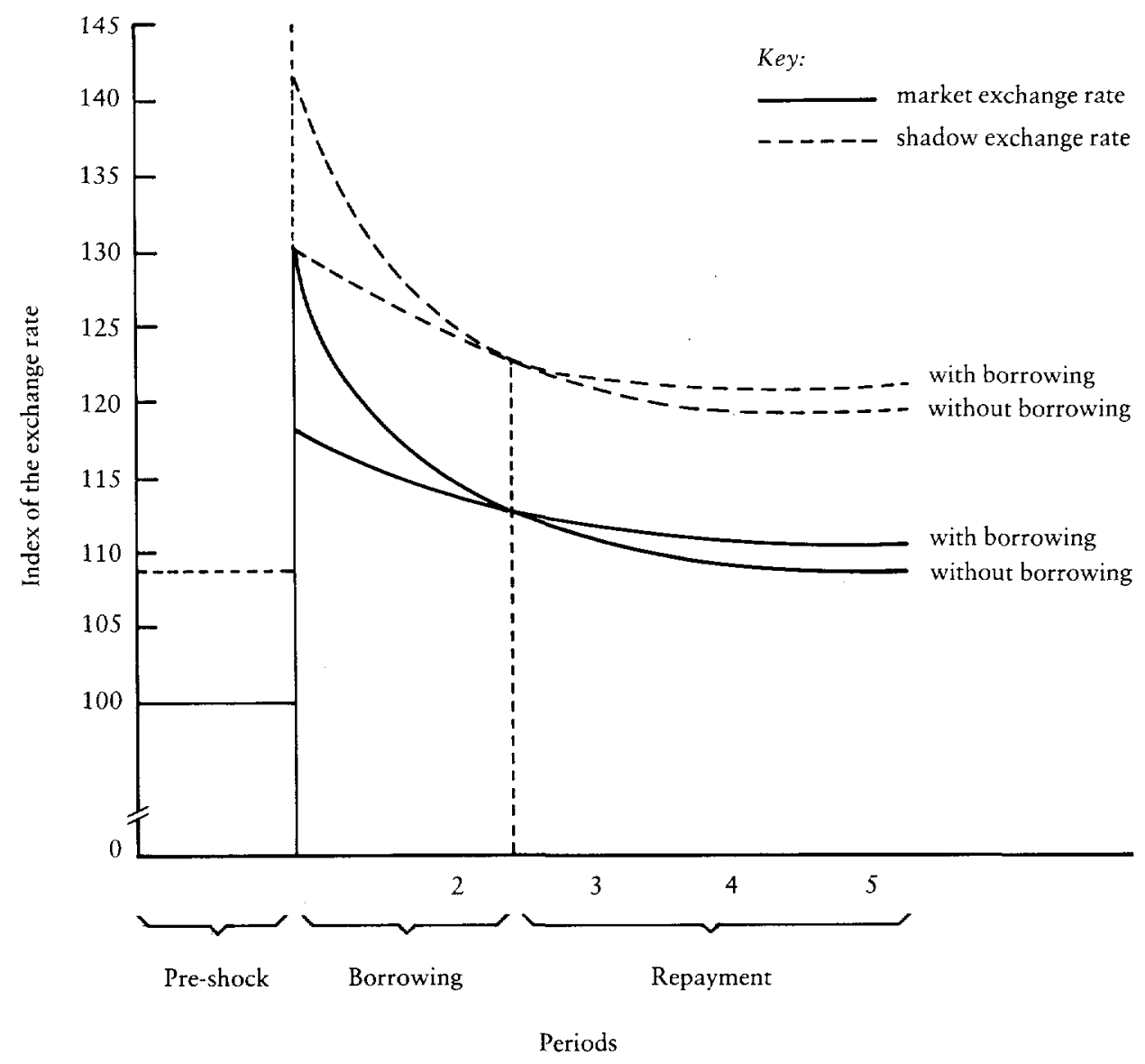

base case parameter values (table 1) and a five-year repayment period. It is assumed that the external shock amounts to 5 percent of the country's GNP.

The immediate effect of the shock is to increase the market and shadow real exchange rate by about 30 percent. As elasticities increase, both rates decline and converge toward a value 9 percent higher than the pre-shock values. The effect of borrowing is to smooth out that path; by borrowing in the first period, both exchanges only go up by about 19 percent during the first year after the shock. With borrowing, however, both exchange rates increase toward a value 11 percent higher than the pre-shock values. The fact that with borrowing, both exchange rates converge toward a higher value than without borrowing, reflects the fact that a surplus has to be generated in order to repay the original borrowing.

\section{Sensitivity to the real interest rate}

The earlier results showed the extra borrowing at a 10 percent interest rate, which is the same rate that is in effect while the pre-shock long-run borrowing 
Table 4. Sensitivity of First-Year Borrowing to the Marginal Interest Rate

\begin{tabular}{cc}
\hline $\begin{array}{c}\text { Spread between new and } \\
\text { previous average interest } \\
\text { rate (percentage points) }\end{array}$ & Borrowing as a percertage of shock \\
\hline+3 & 15 \\
+2 & 20 \\
+1 & 26 \\
0 & 32 \\
-1 & 38 \\
-2 & 44 \\
-3 & 51 \\
\hline
\end{tabular}

strategy is observed; the marginal rate for "adjustment borrowing" is equal to the previous interest rate.

How elastic is this extra borrowing to a marginal interest rate that differs from the previous rate? Table 4 shows such a sensitivity. The marginal rates are expressed as percentage point spreads from the previous average rate, so the results are not sensitive to the level of the previous rate.

The demand for "adjustment" borrowing is shown to be quite elastic to the marginal rate. A marginal rate 3 points higher than the previous one cuts borrowing by half from 32 percent of the shock (table 2) to 15 percent (table 4). A negative (or "concessionary") spread of 3 percentage points increases borrowing from 32 to 51 percent of the shock.

This high elasticity for adjustment finance reflects the potential for important benefits out of policies or international initiatives that reduce interest spreads from commercial sources of credit, particularly when a country is facing an adverse external shock. It is precisely in those situations that these spreads tend to increase: external credit tends to be procyclical. Sirnultaneously, this high elasticity also suggests the large benefits that may accrue out of multilateral lending that finances these programs at interest rates below the marginal rates charged by private sources.

\section{Conclusions}

The main purpose of this article is to develop a framework under which a quantitative relationship could be derived between the magnitude of an external shock, a lagged elasticity response, and the behavior of the market and shadow real exchange rates. An optimal borrowing rule determines the amount of extra borrowing induced by the shock.

The main assumption of the model is exogeneity in the movement of elasticities; they are only a function of time and of the fact that at each moment the market real exchange rate is above the pre-shock equilibrium level. A smoother path of the real exchange rate resulting from additional foreign borrowing does not affect the time path of these elasticities. If the movements of these elasticities were to depend on the size of the price change brought about by the shock, the estimated increase in borrowing would be somewhat smaller. Borrowing reduces 
the initial increase in the value of foreign exchange, so that benefits from bringing foreign exchange from the future toward the present are reduced.

It is important to realize that associated with the optimal borrowing path there is an optimal capital accumulation and investment plan. This plan might be reformulated with the shock and have an effect on external borrowing. This effect is not incorporated into the present analysis. The bias introduced by this omission depends primarily on how changes in the level of investment affect the demand for foreign exchange, because the main rationale for additional borrowing in the present analysis is to reduce variations of the real exchange rate over time. This impact, in turn, depends on the relative "traded goods intensity" of investment and other expenditures. If investment and consumption use traded and nontraded goods in similar proportions, changes in the investment rate will not affect the net demand for foreign exchange. In this case, the present estimates of the model do not have a bias. If investment is more "traded-goods intensive," changes in investment are a substitute for external borrowing in smoothing foreign exchange availability over time. In this case, the present model overestimates the magnitude of external borrowing induced by the shock.

The main reason for borrowing in the model is the change in the time path of the real exchange rate induced by the shock. The model is frictionless; it does not incorporate the effect of probable short-term losses of income during the process of adjustment. These losses might be particularly important under price and wage inflexibility. Incorporating these factors might increase the amount of additional borrowing. In addition to evening out the availability of foreign exchange, external finance could smooth intertemporal income changes induced by short-term unemployment. In this respect, the present results, which do not account for this factor, would tend to underestimate the amount of optimal "adjustment" borrowing.

The fact that a large share of demand for adjustment borrowing is derived at nonconcessionary interest rates suggests that private credit can play an important role in this respect. Nevertheless, although the demand is large, it is quite elastic. Thus, incorporating any "excessive risk" in the private supply of credit to offset creditors' inability to influence and monitor the policies of a borrowing country can have an important welfare cost. The joint involvement of the World Bank and the International Monetary Fund, however, can reduce that risk perception and bring down the cost of that credit. The impact of these lower costs on the quantity of adjustment finance demand can be substantial.

The high responsiveness of borrowing to the marginal rate of interest implies also a large demand for adjustment finance from such organizations as the World Bank, which may be able to provide credit at rates below those of commercial creditors. If the Bank is able to provide that credit at 2 percentage points below the original average rate, following a shock, for example, optimal borrowing increases by more than 35 percent during the first year in our model. Long-term lending also has an important impact on the amount of borrowing, when the speed of convergence of the short-run elasticities to the long-term rates is slow. We find that the possibility of repaying a loan in ten years instead of five in- 
creases an optimal total loan from an amount equal to 30 percent of the shock, to 50 percent of the shock.

It is important to realize that the model assumes that no new distortions are introduced as a result of the shock; neither quantitative restrictions nor new tariffs are adopted to close the balance of payments gap. Only the exchange rate and a neutral aggregate demand policy maintaining full employment are used. The new real exchange rate determines the new system of incentives and thus the reallocation of resources. In this case it is shown that, as a first approximation, the market exchange rate follows a path quite similar to the shadow rate. This means that under perfect foresight and full access of the private sector to world capital markets, the optimal borrowing derived earlier could automatically be carried out by the private sector. In this case, the present analysis would be basically a predictive one. The normative implications for public policy would appear if the earlier conditions do not hold.

\section{Appendix: The Optimal Borrowing Problem}

This appendix describes the formal model used to derive the optimality conditions and numerical simulation results presented in the text. The optimal borrowing problem is defined as one of maximizing the discounted value of real income, subject to market clearing conditions for traded and nontraded goods, and repayment of everything borrowed.

We ignore investment and capital accumulation, so that foreign borrowing is the only instrument available for intertemporal arbitrage after the shock. We also assume a stationary social welfare function, $W(U)$, and constant rates for time preference, $\delta$, and the cost of borrowing, $\rho$.

Let $E_{N}, E_{X}$, and $E_{I}$ be the excess demand functions for nontraded goods, exportables, and importables. We will use double subindexes to indicate the derivatives of these functions with respect to specific prices, $P_{j}$, and real income $U$ for example, $E_{N X}=\partial E_{N} / \partial P_{X}, E_{I U}=\partial E_{l} \partial U$. Later on, we will use $\bullet e_{i j}$ to indicate the elasticity of $E_{i}$ with respect to $P_{j}$. Nontraded goods are the numeraire and traded goods are measured in units that make their (given) international prices equal to one. Thus $P_{N}=1, P_{X}=P$, and $P_{I}=(1+T) P$, where $T$ is the tariff rate on imports, and $P$ is the real exchange rate, defined as the price of traded goods (foreign exchange) in terms of nontraded goods.

The optimal borrowing problem is:

subject to:

$$
\max \sum_{t=1}^{H} W\left(U_{t}\right) \delta^{-t}
$$

$$
\begin{array}{lll}
E_{N}=0 & t=0,1, \ldots, H & \left(\lambda_{t}\right) \\
E_{I}+E_{X}=B_{t}-Z_{t} & t=0,1, \ldots, H & \left(\lambda_{t} P_{t}^{*}\right) \\
\sum_{t=0}^{H} B_{t} \rho^{-t}=0 & & (\Psi) .
\end{array}
$$


$B_{t}$ is net foreign borrowing in period $t$ and $Z_{t}$ represents a (negative) external shock in that period, so that equation A-2 simply requires that net financing cover the cost of the excess of imports over exports. Equation 3 is the repayment constraint.

The symbols in parentheses beside the equations are the Lagrange multipliers associated with the $(2 H+1)$ constraints. Thus, $\lambda_{t}$ is the social value of one additional unit of nontraded goods available in period $t ; \lambda_{t} P_{t}^{*}$ is the social value of traded goods in $t$, so that $P_{t}^{*}$ is their value in terms of nontradables, that is, the shadow real exchange rate. The constant $\Psi$ is the present value of relaxing the repayment constraint, which is equivalent to the value of foreign exchange in period 0 .

The optimality conditions are:

$$
\begin{gathered}
E_{N N}+P_{t}^{* \prime}\left(E_{X N}+E_{I N}\right)=0 \\
\lambda_{t} P_{t}^{*}=\Psi \rho^{-t} \\
d W / d U_{t} \delta^{-t}=\lambda_{t}\left(E_{N U}+P_{t}^{*} E_{X U}+P_{t}^{\prime} E_{I U}\right) .
\end{gathered}
$$

Equation A-4 defines the shadow real exchange rate $P_{t}^{*}$. By using the homogeneity condition, $E_{N N}+P E_{X N}+P(1+T) E_{I N}=0$, it can be transformed to show that $P^{*}$ is a weighted average of the real exchange rate as received by exporters $(P)$ and paid by importers $(P+P T)$, with weights proportional to the price responsiveness of exports and imports, respectively.

$$
P^{*}=P \frac{\left[E_{X N}+(1+T) E_{I N}\right]}{E_{X N}+E_{I N}}
$$

If the cross-elasticity between imports and exports is zero, $E_{X N}=-E_{X X}$ and $E_{I N}=-E_{M}$, so that equation A-7 above reduces to equation 7 in the text. In addition to $E_{X I}-0$, equation 7 in the text assumes that initially $E_{X}+E_{I}=0$, so that equation 7 can be directly interpreted in terms of elasticities.

Condition A-5 states that the present value of traded goods must decline at the rate of interest paid on foreign loans; otherwise there would be obvious opportunities for gains through arbitrage between the present and the future, via borrowing-repaying. The value of traded goods has two components: the shadow real exchange rate, $P^{*}$, and the value of income in terms of nontraded goods, $\lambda_{r}$.

We can rewrite condition A- 6 as:

$$
\lambda_{t}=\frac{\delta^{-t} d W / d U_{t}}{E_{N U}+P_{t}^{t} E_{X U}+P_{t} E_{I U}}
$$

so there are three elements determining the evolution of $\lambda_{t}$ : the social rate of time preference, $\delta$; the marginal value of real income, $d W / d U_{t}$ (which tends to reduce $\lambda_{t}$ when real income is large and increase it when society is poorer); and the denominator in this expression, which is what allows us to go back from the real income numeraire of $W(U)$ to units of expenditure in terms of nontraded goods. Note that in the absence of tariffs the denominator would simply be $-E_{U}=\partial E /$ $\partial U$, the change in expenditures needed to obtain one more unit of real income. 
For the analysis of the next section, it is convenient to substitute $\lambda_{t}$ and $P_{t}^{*}$ from equations A-4 and A-5 to obtain:

$$
d \mathrm{~W} / d U_{t}=\Psi(\delta / \rho)^{t} E_{U}\left[1+J\left(\frac{m_{N} e_{N I}}{e_{N N}-m_{I}}\right)\right]
$$

where $m_{N}$ and $m_{I}$ are the marginal propensities to consume nontraded and importable goods, $\left(m_{I}=P_{i} E_{W} / E_{U}\right) ; J=T /(1+T)$, which is the proportional tariff rate, and $e_{N I}=$ elasticity of $E_{N}$ with respect to $P_{i}$, for $i=N, I$.

\section{Effect of external shocks}

We assume now that after the economy has settled on an optimal borrowing plan, as defined by equations A-1 through A-6, there is an increase in $Z_{t}$, disturbing the equilibrium. The problem is to determine how the path for $B_{t}$ should change as a result of the shock. The answer is obtained by differentiating the conditions defining the equilibrium with respect to $Z_{t}$.

Let $p_{t}$ and $u_{t}$ indicate the proportional changes in $P_{t}, U_{t}$, and $b_{t} ; z_{t}$ will denote the change in $B_{t}$ and $Z_{t}$ as a proportion of total expenditures in the period. Then from equations $\mathrm{A}-1$ and $\mathrm{A}-2$ :

$$
\begin{gathered}
e_{N N} \cdot p_{t}+e_{N U} \cdot u_{t}=0 \\
\left(1-J \cdot m_{I}\right) u_{t}-J \theta_{I} e_{I N} p_{t}=b_{t}-z_{t}
\end{gathered}
$$

where $\theta_{I}=$ share of imports in total expenditures and $e_{N U}=$ income elasticity of nontraded goods.

The repayment condition in terms of additional borrowing is:

$$
\sum_{t=1}^{H} b_{t}\left(\frac{g}{p}\right)^{t}=0
$$

with $g=$ growth in GNP (this is necessary by the normalization of changes in $B_{t}$ by the size of the economy).

Differentiation of the optimal borrowing conditions is less straightforward because they are defined in terms of derivatives of the excess demand functions, so that explicit assumptions about "higher order" behavior of these functions is required. It is assumed that within each period the marginal propensities to consume and excess demand elasticities are constant. Then from equation A-8:

$$
\frac{d \Psi}{\Psi}=\phi u_{t}+m_{N} p_{t}
$$

where $\phi=$ elasticity of the marginal utility of real income, $d W / d U_{t}$, with respect to $U_{t}$.

This system, equations 9 through 12 , can readily be solved for $p_{t}, u_{t}$, and $b_{t}$ as a function of $z_{t}$. The results are reported in the text. 


\section{REFERENCES}

Balassa, B. 1986. "Policy Shocks in Developing Countries." American Economic Review 76, no. 2 (May): $75-78$.

Dornbusch, R. 1974. "Tariffs and Non-Trade Goods." Journal of International Economics, no. 4.

Kharas, H. and H. Shishido. 1985. "Thailand An Assessment of Alternative Foreign Borrowing Strategies," World Bank Staff Working Paper, no. 781.

van Wijnbergen, S. 1984. "Macro-economic Aspects of the Effectiveness of Foreign Aid: On the Two-Gap Model, Home Goods Disequilibrium and Real Exchange Rate Misalignment." World Bank Development Research Department. Washington, D.C. Processed. 